\title{
DEPORTE, SOCIABILIDAD E IDENTIDADES EN NICARAGUA (1901-1924)
}

\section{SPORT, SOCIABILITY AND IDENTITIES IN NICARAGUA (1901-1924)}

\author{
Chester Urbina Gaitán*
}

\section{RESUMEN}

Hacia finales del siglo xix, Nicaragua se vinculaba en forma estable al sistema económico mundial, lo cual permitió la llegada de nuevos productos y prácticas culturales, entre ellas el deporte. En este sentido, el objetivo central de este artículo es analizar el papel del deporte en la sociabilidad de los sectores sociales nicaragüenses, el papel del Estado y de la Iglesia católica en el control social y la promoción de esta actividad, así como, las identidades que promovió y reforzó el deporte durante los años 1901-1924. Para este análisis se tomaron en cuenta los principales periódicos de circulación nacional y el Diario Oficial. Entre las principales conclusiones, se recalca el béisbol como el deporte que más rápidamente se identificó con la población nicaragüense debido a que empezó a perder su carácter clasista y la población trabajadora empezó a tomar participación en su práctica.

PALABRAS CLAVE: NICARAGUA * DEPORTE * ESTADO * PRENSA * IGLESIA * CATOLICISMO

\section{ABSTRACT}

At the end of the nineteenth century, Nicaragua was linked in a stable way to the world economic system, which allowed the arrival of new cultural products and practices, among them sport. In this way, the central objective of this article is to analyze the role of sport in the sociability of Nicaraguan social sectors, the role of the State and the Catholic Church in social control and the promotion of this activity, as well as the identities which promoted and reinforced the sport during the years 1901-1924. For this analysis were considered the main newspapers of national circulation and the Diario Oficial. Among the main conclusions, baseball is emphasized as the sport that most quickly identified with the Nicaraguan population because it began to lose its class character and the working population began to take part in its practice.

KEYWORDS: NICARAGUA $*$ SPORT * STATE $*$ PRESS * CHURCH * CATHOLICISM

Instituto de Estudios Latinoamericanos (IDELA) de la Facultad de Filosofía y Letras de la Universidad Nacional de Costa Rica.

chesterurbina@yahoo.com 


\section{INTRODUCCIÓN}

La vinculación formal de Nicaragua al mercado mundial se logro por medio del cultivo y la comercialización del café. El café fue promovido durante el régimen de José Santos Zelaya (1893-1909), quien puso las bases jurídicas, políticas, económicas y sociales para la modernización del Estado nicaragüense (Vargas, 1989). Con la caída del poder de Zelaya, se da el ascenso de la burguesía conservadora quien permite la ocupación estadounidense con la esperanza de una paz social y una prosperidad económica garantizada. La burguesía conservadora pretendía que el pueblo compartiera su actitud, pero no lo consiguió. Imputaron la reprobación popular contra la ocupación a la falta de preparación política de las masas. Justificaron la intervención, en la supuesta anarquía que reinaba en Nicaragua (Vargas, 1989). Durante los años de ocupación extranjera, el Estado nicaragüense no tuvo independencia del capital extranjero. La dominación económica y financiera permitió que los banqueros estadounidenses controlaran el presupuesto de Nicaragua, decidieran las mejoras que se tenían que hacer y determinaran los montos que el país tenía que gastar mensualmente en el mantenimiento de su propio Estado (Vargas, 1989).

En medio de este contexto, la clase controladora del Estado siguió una línea de pensamiento - que según Steven Palmer - a un nivel general, rechazaba la legitimidad de las doctrinas eugenésicas ortodoxas, al imaginar soluciones al llamado "problema del indio", y en su lugar enfatizaron la asimilación cultural y biológica. Esto contrasta con la postura de los intelectuales costarricenses, que tendieron a adoptar cada vez más los supuestos del darwinismo social en su empeño por concebir una nación de raza homogénea que debía ser protegida de la contaminación racial (Palmer, 1996). Aunado a lo anterior, la intervención profundizó la debilidad del estado nicaragüense y redujo aún más su capacidad institucional de dar respuesta a los problemas sociales de la población, especialmente en lo que se refiere a la salud pública. La poca incidencia del Estado en la salud pública, estaba a cargo de las municipalidades, que apoyándose en el Reglamento de la Policía $y$ en sus pocos recursos económicos trataban de impulsar y hacer que la población cumpliera con las medidas elementales de higiene. Nunca como en otros momentos, el deterioro del estado de salud de la población fue tan evidente, con epidemias como la varicela, el sarampión, la influenza, tifoidea, malaria, situación que se veía agudizada por las condiciones higiénicoambientales en que vivían las personas, la falta de infraestructura sanitaria, bajo nivel educativo y la desarticulación de la organización sanitaria. Todo esto frustró el plan de la Fundación Rockefeller de erradicar la uncinariasis en los núcleos urbanos y semirrurales del país (Peña, 2002; Palmer, 2005). Esta incapacidad del Estado nicaragüense por elevar el nivel sanitario $y$ físico de sus ciudadanos también se vio reflejada en la poca promoción del deporte a un nivel nacional a principios del siglo xx.

El advenimiento del deporte moderno en Nicaragua ocurre en medio de un contexto cultural donde en las fiestas patronales existían juegos de danza, de los cuales unos tienen su origen en el tributo que los indígenas ofrecían a sus divinidades, mientras que otros se originan en la conquista $y$ tenían como fin entretener al pueblo con motivo de la celebración de las fiestas religiosas. Entre los principales juegos de danza destacan: Los Chinegros, La Vaca, El Toro Guaco, El Toro Encohetado, El Toro Venado, La Yegua, Los Mantudos, Moros y Cristianos, Los Diablos, Las Inditas, La Gigantona, El Enano, El Macho Ratón, El Gigante, El Tabureteado, etc. (Berrios, 1960; Guerrero y Soriano de Guerrero, 1965).

Sobre la introducción del deporte en Costa Rica, Guatemala y El Salvador se conoce que esta actividad cultural está vinculada con las practicas realizadas por las principales colonias extranjeras radicadas en esos países a finales del siglo XIX y que debido a sus lazos socio afectivos con la burguesía nacional y a sus intereses económicos en el café y al banano, era de esperarse que los primeros clubes deportivos de estos países promovieran la identidad de clase de esos sectores. De esto se desprende que las primeras asociaciones deportivas ejecutaran actividades que solo estaban al alcance de sus integrantes, debido a que ellos tenían el 
suficiente tiempo libre, dinero y preocupación por su salud y apariencia física, aspectos que les permitieron mantener sus clubes, los cuales tenían un carácter clasista y exclusivo (Urbina, 2001, 2006 y 2007)

Acerca de las obras que brindan información sobre el deporte en Nicaragua a finales del siglo xix, Salomón Barahona y Cesar Vivas en 1972 señalan respecto al béisbol, que en 1891 se formó en Managua la entidad deportiva Sociedad de Recreo para la práctica del deporte. Estaba integrada por estudiantes nicaragüenses provenientes de los Estados Unidos. El presidente de esta agrupación era el Dr. Adán Cárdenas, ex Presidente de la República. Estas personas formaron luego el Managua Base-Ball Club y el "Granada". En julio de 1891, realizaron un partido en el trillo de los Fallas en Managua (Barahona y Vivas, 1972).

Sobre los partidos jugados por estas asociaciones no existe ninguna referencia en los periódicos nicaragüenses. Jorge Eduardo Arellano repite en el 2007 lo mismo que refieren Barahona y Vivas, por lo que su estudio es de carácter anecdótico y carece de respaldo a nivel de fuentes periodísticas (Arellano, 2007). Sobre el ciclismo se conoce que en el plano topográfico de la finca "La Nina" del hotelero italiano don José Lupone, aparece un velódromo con sus tribunas y un restaurante (Falcinelli,1898; Belli, Mantica y Caldera, 2011).

Con respecto al origen del boxeo en el país, Richard McGehee (2000) ha brindado algunos datos incompletos. En cuanto al fútbol, se sabe que uno de sus principales promotores fue don Napoleón Parrales Bendaña, quien lo aprendió durante su estadía en Costa Rica. Al regresar al país, lo enseñó en Diriamba, con el fin de que la población lo comenzara a practicar. Otra versión señala que la burguesía diriambina enviaba a sus hijos a estudiar a Europa, los cuales al retornar en 1907 fundaron la "Sociedad de ahorro", cuyo fin era el de recaudar fondos para el fomento y la práctica del balompié en la ciudad, y finalmente, se practicó el primer partido oficial en el año de 1910.

Acerca de la enseñanza de la gimnasia en la última década del siglo xIx, el Diario de Nicaragua (1895) señala que a mediados de septiembre de 1895, Gastón Schiffmann había sido nombrado como profesor de canto, calistenia, gimnasia y ejercicios militares de la escuela primaria superior de varones de Managua.

Según se ha visto, en Nicaragua han existido varios autores que han ofrecido diversas versiones acerca del origen de la práctica social del deporte. No se pretende desechar en su totalidad el aporte que se ha hecho en ese sentido, pero es a la luz de sus deficiencias e imprecisiones que se plantea la necesidad de delimitar más exactamente la génesis del fenómeno deportivo en el país. Fundamentado en lo anterior, es que el presente documento tiene como objetivo estudiar el origen del deporte en Nicaragua desde la fundación del Club de béisbol New York en 1901 - primera asociación deportiva de Nicaragua, hasta 1924- año en que el béisbol obtiene la categoría de representación nacional. Con esto se pretende analizar el papel que tuvo el deporte en la sociabilidad de los sectores sociales nicaragüenses; el papel del Estado y de la Iglesia católica en el control social y promoción de esta actividad; las identidades que promovió y reforzó el deporte en $\mathrm{Ni}$ caragua durante los años de estudio y por qué el béisbol se diferenció de las demás disciplinas deportivas. Para este fin se estudiara el inicio de las prácticas deportivas en el país, los lugares donde se efectuó su ejecución, los nombres de los primeros deportistas y sus promotores, la posición de la Iglesia católica, el control social y la promoción del Estado hacia la actividad deportiva. Lo anterior se realizará a través de la información que brinden los periódicos de circulación nacional. La posición del Estado se verificara con la revisión del Diario Oficial.

\section{DEPORTE, SOCIALIZACIÓN E IDENTIDADES EN NICARAGUA (1901-1924)}

El primer club deportivo nicaragüense, del cual consta su existencia en la prensa nacional fue el Club de béisbol New York de Managua, que para el 21 de diciembre de 1901 dejaba registrados sus estatutos ante el Poder Ejecutivo. $\mathrm{Su}$ directiva quedó conformada de la siguiente manera: Capitán, Carlos Castillo h.; Vicecapitán, Feliciano Ortiz; Tesorero, Pablo J. Medrano h.; Secretario, J. J. Ubieta; Miembros: J. Leoncio 
Ardón, Carlos Salas, Genaro Álvarez, Terencio García h., Teófilo Medrano M., Marcos Quezada h. y Carlos Flores B. (Diario Oficial, 03/01/1902, p. 3-4). Para el domingo 19 de enero de 1908 a las tres y treinta de la tarde, en el trillo de los señores Solórzano, se realizó un desafío de béisbol, entre los clubes Managua y Unión, con una apuesta de cien pesos. Los pitchers de los clubes fueron: por el Managua, Sebastián Arana y por el Unión, Francisco Solórzano (El Comercio, 1908, p.2).

El 20 de agosto de 1913 jugaron en el Campo de Marte los clubes Boer y Venus. Ganó el Venus nueve carreras contra cinco del Boer (El Comercio, 20/08/1913, p.2). El domingo 24 de octubre se realizaron los siguientes partidos de béisbol: de 8 a 10 am jugaron los mariners del capitán Rixey con el club Emperador; de 10 am a 1 pm el club Japón y el Boer y de 3 a 5 pm el Managua contra los mariners del buque Yorktown (El Comercio, 24/10/1913, p.2). Para el domingo 13 de diciembre de 1914, se efectuó en el campo de deportes de los señores Martínez y Compañía de Granada un partido entre el Managua y el Boer. Este último perdió once carreras a ocho. Entre lo más sobresaliente del partido están los veinte ponches del pitcher del Managua (El Diario Nicaragüense, 15/12/1914, p.2 ). La actuación del lanzador es importante, porque se dio en una sociedad agraria donde la habilidad para ejecutar algo brindaba cierto "status" (Urbina, 2000, p. 66).

El Boer estaba integrado por artesanos $y$ trabajadores capitalinos - lo cual se comprobara más adelante - sin embargo; el béisbol no se convirtió en un canal de expresión de la lucha de clases. La profundización de la crisis económica por la política deflacionaria y recesiva que se implementó durante la ocupación norteamericana, se tradujo en mayor desempleo $y$ caída de los salarios reales de los asalariados; $y$ el sentimiento de antiimperialista de los sectores organizados del artesanado, se reflejaron en un sentimiento de rechazo en contra de la ocupación (Vargas, 1989). No obstante, durante la ocupación estadounidense hay un estancamiento relativo de los movimientos sociales y las clases explotadas arrastran en silencio su carga o se restringen a formas de luchas aceptables para las clases explotadoras: huelgas limitadas a reivindicaciones económicas, la creación de sindicatos, etc. (Vargas, 1989). Por otra parte, debe aclararse que la propagación del béisbol fuera del área urbana de Managua se debe fundamentalmente al ferrocarril, el cual para principios del siglo xx vinculaba el puerto de Corinto en el océano Pacífico con las ciudades de Chinandega, León, Managua, Masaya y Granada (Boletín Nicaragüense de Bibliografía y Documentación, 1979).

Para mayo de 1915, los clubes managüenses: Manchester, Imperio, Xolotlán, Boer y Managua establecieron la Confederación Deportiva de Béisbol de Managua, con el fin de establecer un pacto de amistad entre esos clubes. Esto se debió a los sucesos trágicos ocurridos el 30 del mes antes citado en la ciudad de Masaya, donde los peloteros del club Managua fueron agredidos por fanáticos de esa localidad (El Diario Nicaragüense, 11/06/1915). En 1917 existía una Liga Nacional de béisbol ( $E l$ Imparcial, 02/10/1917, p. 2). El domingo 13 de noviembre de 1916, hubo un partido de béisbol entre el Peña Caliente y los marinos del Campo de Marte. Se cobró la entrada al partido, la cual arrojó un total de 46 córdobas. A pesar de que los señores Manuel Gutiérrez Peña, Jacobo Tefel y Francisco Frixione ofrecieron 20 córdobas a los del Peña Caliente para que ganaran, el club nacional perdió 11 carreras a 7, por lo que en el periódico El Comercio (07/11/1916) se señaló que no fue interesante. Otro factor que ayudó a la popularización del béisbol fue que se les permitió a los niños su práctica, a modo de ejemplo, el jueves 1 de noviembre de 1917, el club de béisbol infantil Filadelfia venció al Minerva de Masaya en el campo de aquella ciudad (El Imparcial, 04/11/1917).

Posteriormente, a finales de octubre de 1917, el Club Atlético de la capital estaba acondicionando su terreno de prácticas para una mejor ejecución del béisbol, fútbol y tenis. Se construirían dos cuadros para patinar al aire libre. También se había hecho el trazo para la pista de coches $y$ bicicletas, $y$ se estaban pidiendo varios botes para las regatas en el lago de Managua. Las obras estaban dirigidas por el ingeniero Portocarrero (El Imparcial, 24/10/1917). 
Otro elemento que ayudó a popularizar aun más al béisbol y que le dio un carácter de deporte nacional, fue que en el partido que se efectuó el domingo 13 de enero de 1918, entre los clubes Managua y Granada, asistió el entonces Presidente de la República General Emiliano Chamorro (El Heraldo, 15/01/1918). La asistencia a este partido por parte del presidente Chamorro le dio al béisbol el carácter de "deporte nacional", aunque el verdadero interés de este político, era el obtener buena imagen ante el pueblo, ya que llegó al poder a través de unas elecciones en las que no participaron los liberales (Delgado, 1992).

Un factor que le dio al béisbol el carácter de cohesionador nacional, fue la participación del club Bluefields de la costa caribeña en el campeonato de primera división del país de 1918 (El Heraldo, 12/04/1918). Esto contribuyó a que a mediados de agosto del año antes mencionado, las ciudades de Ocotal y Somoto -en el norte del país - fundaran sus propios clubes de béisbol (El Heraldo, 13/08/1918). A inicios de setiembre de 1919, en San Rafael del Sur se estableció un club béisbolero llamado San Rafael. El estadounidense R. W. Malcolmson era su Presidente Honorario (La República, 05/09/1919).

Sobre los hechos de violencia que ocurrían en algunos partidos, se sabe que para el 30 de mayo de 1915, en la ciudad de Masaya, los peloteros del Club Managua fueron agredidos por fanáticos de esa localidad (El Diario Nicaragüense, 11/06/1915). También se dispone de la información brindada por La Noticia del martes 5 de noviembre de 1917, donde se refiere que en un encuentro deportivo en la ciudad de Granada, entre el San Fernando de Masaya y el Granada, triunfó el primero cuatro carreras contra una. Durante el partido se dieron los insultos de la barra granadina para los masayenses. Cada vez que Julián Amador tomaba el bate le gritaban: "¡Baila el toro huaco! igarrobo! Garrobo!”. Al terminar el partido, los jugadores del San Fernando fueron golpeados por los granadinos, habiendo sido agredidos en el parque por un grupo como de veinte individuos. El cátcher Reinaldo Sánchez resultó muy golpeado ( $\mathrm{La} \mathrm{No-}$ ticia, 17/10/1917). Estos incidentes se siguieron repitiendo, por lo que para mediados de junio de 1922, el árbitro de béisbol Pedro Joaquín Miranda fue golpeado con furia por chinandeganos, luego de un partido entre el Club Federal de Chinandega y el Club La Libertad de León (La Tribuna, 18/06/1922).

Acerca de los actos de violencia en partidos de un deporte de combate entre dos equipos, Norbert Elías (1992) señala que la mayoría de los jóvenes espectadores protagonistas de la violencia en el fútbol - o en el béisbol- vivirían una vida vacía y sin excitación, quizá con poco deporte $y$ poco gusto en practicarlo, con una escasa vivencia de actividades de ocio, sin ninguna perspectiva y meta personal. Los encuentros deportivos locales se convertirían en un gran acontecimiento desrutinizador $y$ en una oportunidad, dado el entusiasmo que brinda la congregación de cientos o miles de individuos en esa misma condición, de expresarle al mundo que también están presentes. Los estragos a bienes públicos y privados, así como, las peleas, serían la venganza contra los poderes establecidos o contra el causante, no siempre claro, que les ha hecho una gran injusticia (Elias y Dunning, 1992). Por otra parte, Dunning refiere que:

la probabilidad de la violencia de los espectadores en el contexto del fútbol - o en el béisbol- está probablemente exacerbada por el grado en el que los espectadores se identifican con los equipos participantes y con la intensidad de su inversión emocional y su compromiso con la victoria de los equipos a los que alientan. (...) A su vez, la intensidad de la inversión emocional de los espectadores en la victoria de sus equipos está vinculada a la centralidad y significación del fútbol —o del béisbol—en sus vidas, esto es, si es una entre un número de fuentes de sentido y satisfacción para ellos, o si es la única (Dunning, 1999).

Estos hechos de violencia se dieron en una sociedad ávida de nuevos entretenimientos $y$ emociones, ocupada militarmente por los Estados Unidos, por lo que el béisbol se convirtió en una válvula de escape a la presión social. 
Sobre la utilización de un garrobo en los partidos de béisbol, Jorge Eduardo Arellano señala que en 1916, los fanáticos fernandinos iniciaron la costumbre -que se conservaría hasta 1924- de soltar en el terreno un garrobo, adornado con cinta de papel, antes de empezar el juego, para traer mala suerte al equipo visitante. Los granadinos usaban igual procedimiento y el garrobo, bien cuidado, lo llevaban a otras localidades como mascota. Los masayas enterraban el garrobo en una de las bases. Esto dio origen al dicho que se aplicaba por un largo tiempo a quien tenía "tuerce" o mala suerte: "tiene su garrobo enterrado" (Arellano, 15/01/2015).

La referencia del toro huaco en los partidos de béisbol, se hacía porque las personas que asistían como espectadores de una nueva diversión - como lo era este deporte- encontraban en ambas actividades dos similitudes: las dos se ejecutaban entre dos equipos de personas y en nueve momentos diferentes.

El toro huaco es un baile que lo ejecuta un conjunto de bailantes divididos en dos grupos. Cada uno consta de ocho a doce personas. Durante el baile surge el personaje "Mandador", que es el jefe del baile y un "Toro" artificial: un individuo que carga una cabeza de toro montada sobre un armazón. Aunque el baile tenga un jefe llamado "Mandador", cada grupo tiene un Capitán. La danza se realiza al compás de un pito y un tambor. Cada grupo se ubica en fila india a cada lado de la calle, en orden de estatura. En el centro va el toro $y$ el mandador a la cabeza del baile. La representación consiste en una serie de saltos o brincos, diferentes entre sí, que los bailantes verifican de acuerdo con nueve sones distintos (http://www.diriamba.info/El\%20 Toro\%20Huaco.htm).

Esto remite a la forma cultural en que fue apropiado el béisbol en Nicaragua, donde los nicaragüenses pertenecientes a los sectores populares lo hicieron con base en su posición en la jerarquía de clase. Al respecto, Duby señala:
En verdad el sentimiento que experimentan los individuo y los diversos grupos sociales respecto a su propia posición, asî como los comportamientos que de ellos se desprenden, no están inmediatamente determinados por la realidad de su condición económica, sino por la imagen que ellos se hacen de aquella, que no resulta fiel a la realidad, pero está influida siempre por el juego de un complicado conjunto de representaciones mentales (1976, p.8).

Para 1923, los clubes de béisbol estaban mejor organizados, debido a que se tiene conocimiento de que el Club Libertad de León tenía como su representante al Dr. Ricardo Wassmer (La Tribuna, 04/03/1923). Los partidos de béisbol que se jugaban en la calle, dejaban a veces personas golpeadas, por lo que la policía intervenía capturando a los jugadores callejeros. A principios de mayo del año antes citado, se sabe que Manuel Aburto estaba practicando este deporte en la calle y le dio un bolazo en el pómulo izquierdo a la señorita Francisca T. Gómez, por lo cual el jugador fue apresado (La Tribuna, 02/05/ 1923). A principios de febrero de 1924, el club Boer había jugado en San Salvador dos partidos con los mejores clubes salvadoreños. El primero se verificó el domingo 3 de febrero, donde ganó doce carreras contra cero. En el segundo encuentro que se realizó el 10 de febrero, triunfó catorce carreras contra cero. Al club Boer se le obsequió una copa de plata por el presidente Quiñones. También fueron condecorados varios jugadores por una hija del presidente salvadoreño (Nicaragua Informativa, 22/01/1924).

Sobre la selección nacional de béisbol que representó a Nicaragua en la Olimpiada Centroamericana realizada en Costa Rica entre finales de diciembre de 1924 y principios de enero de 1925, se conoce que los integrantes de esta delegación deportiva eran: Salvador García Valery, Santos Ramírez h., Octavio García Valery, Francisco Soriano, Gilberto Miranda, Manuel Calero, Miguel Barrios, Francisco Acosta, Francisco Monterrey, José Madriz, Julio Paniagua, Eliseo Largaespada, Edmundo López, 
Enrique Miranda, Marcelino Mayorga, Pablo Escke, Ernesto Escke y Guillermo Escke ( $L a$ Tribuna, 09/01/1925). La prensa nacional no refiere el resultado de los partidos jugados por esta selección; sin embargo, el periódico costarricense La Tribuna señala que el primer partido era el miércoles 31 de diciembre de 1924 contra Costa Rica, pero como esta no se presentó al campo deportivo, Nicaragua ganó por default (La Tribuna, 01/01/1925). En el segundo partido, nuevamente el país gana por default contra el equipo de la Zona del Canal de Panamá (La Tribuna, 04/01/1925). En el último encuentro Nicaragua triunfo sobre Costa Rica por seis carreras contra una (La Tribuna, 06/01/1925).

Para el domingo 20 de marzo de 1904, a las cuatro de la tarde, se efectuaron unas carreras ciclísticas en la finca "Nina" de don Federico Lacayo. Se daría una competencia entre el señor Lacayo y don Alcibíades Fuentes hijo. Asimismo, se sabe que existían grandes apuestas por parte de los aficionados a este deporte ( $E l$ Comercio, 20/03/1904). Hacia mediados de julio de 1905, en Managua, se estableció la asociación ciclística Veloz Club que aglutinaba a los amantes de este deporte. Su directiva era la siguiente: Presidente, don Bernabé Portocarrero; Vicepresidente, don Elie J. Hazera; Secretarios, don Alberto C. Ramírez y don T. Lacayo; Vocales, don Tomás A. Vargas, don Domingo Calero D., don Ernesto Portocarrero, don José Solórzano h., don Francisco Fixione y don Benito Castellón; Tesorero, don Samuel Portocarrero (El Comercio, 14/07/1905). Sobre don José Solórzano se sabe que fue Alcalde de Managua en 1922 y tuvo el rango de General (Manfut, 2008).

Posteriormente, para el domingo 30 de julio de 1905, en la finca "Nina" se llevaron a cabo unas carreras ciclísticas dedicadas al hospital de Managua. Se realizaron cinco carreras, dos de ellas de de cinta. Lisímaco Lacayo h. y Francisco Frixione compitieron en la segunda carrera, en tanto que Daniel Frixione h. lo haría en la tercera contra Vicente Molieri ( $E l$ Comercio, 23/07/1905). Para el 6 de agosto, se verificaron otras carreras de bicicletas por parte del Club Ciclista Fernandino de Masaya a beneficio de la Asociación de Damas de la Caridad.
El uniforme que vestían los ciclistas estaba formado por una camisa de punto de color aplomado, a rayas negras, pantalón café claro, gorrita del mismo color $y$ calzado $y$ medias negras. El club lo integraban cerca de treinta socios. Las carreras se realizaron en el orden siguiente: Rodrigo Velázquez contra Julito Medal; ganó el primero. Humberto Caldera contra Armando Maison; ganó el primero. Ernesto Noguera contra Marcelo Ortega; ganó el segundo. Ernesto Astacio contra Rigoberto Rosales; ganó el primero. Gustavo Alemán B. contra E. Castaño; ganó el primero. Alberto Noguera contra Alfonso Gutiérrez A.; ganó el segundo. Paco Robles contra Dagoberto Prado; ganó el primero. En la carrera de lentitud entre Carlos Velásquez y Rigoberto Rosales, triunfó Velásquez. Después se verificaron las de cintas en las que contribuyeron muchas señoritas enviando listones lujosamente bordados. En la noche, los ciclistas pasaron al Hotel, donde fueron obsequiados con una copa de coñac por doña Josefana de Azcárate, la propietaria de este establecimiento $(E l$ Comercio, 09/12/1905).

Sobre el balompié, se sabe que el 15 de septiembre de 1909, se efectuó un partido entre dos equipos, compuestos por socios del Managua Sporting Club. El encuentro se verificó en el trillo de los señores Frixione. El equipo Blanco, ganó por dos goles a uno al equipo Azul y Blanco. E. Solís y Francisco Frixione anotaron los dos tantos del equipo Blanco y por el perdedor, anotó el gol Julio D`Arbelles (El Comercio, 17/09/1909).

Los deportistas nicaragüenses de principios del siglo xx, no eran constantes en sus prácticas y en el sostenimiento de sus asociaciones deportivas, por lo que tuvieron una existencia efímera. La ejecución del deporte era vista como un acto social más de los jóvenes acomodados, $y$ no como una actividad que demandaba disciplina y esfuerzo para realizarla. Lo anterior se ilustra con el hecho de que a finales de 1917, el club managüense Metropolitano volvió a realizar prácticas deportivas, después de una temporada de haber desaparecido (El Imparcial, 15/11/1917).

Para el 25 de diciembre de 1917, el Club Metropolitano de Managua concertó un partido 
de fútbol con un club de Chinandega, el cual se realizó en aquella ciudad (El Imparcial, 07/12/1917). En 1920, el balompié logró obtener el carácter de representación nacional, debido a que para el domingo 29 de febrero del año en mención, se efectuó en Managua, el primer partido de este deporte entre unos futbolistas costarricenses y una selección nacional de fútbol de Nicaragua. El partido concluyó con un empate a un gol (El Diario Nicaragüense, 02/03/1920). Posteriormente, para el domingo 12 de diciembre de 1920 se realizó un partido entre el Xolotlán y el equipo de los Hermanos Cristianos (La Noticia, 07/12/1920). El domingo 14 de agosto de 1921 se ejecutó un partido entre los clubes Xolotlán y Diriangén de Diriamba. Este último practicaba diariamente bajo la orientación de don Carlos A. González ( $L a$ Noticia, 09/08/1921).

Con respecto al origen del atletismo, se sabe que para el viernes 4 de julio de 1913, en el Campo de Marte, los mariners estadounidenses celebraron el aniversario de la independencia de los Estados Unidos con ejercicios como los siguientes: carrera de piernas, carrera y salto, tiro al blanco a 100 yardas, salto de altura, salto con obstáculo, tiro del martillo, carrera de caballos en diligencia, lucha y boxeo (El Comercio, 04/06/1913).

Acerca del cricket se señala que el martes 1 de octubre de 1917, dos grupos de señoritas de le elite capitalina comenzaron a practicar este deporte en el campo de la Momotombo. Esto lo hacían con el objeto de adiestrarse y poder jugar en público partidos a beneficio del hospital de Managua. Posteriormente, se suponía que jugarían al tenis, al baloncesto y otros deportes. Estas señoritas señalaron que los días martes y sábados se reunirían por las tardes a practicar (El Imparcial, 04/10/1917). Acerca del campo deportivo de la Momotombo, debe aclararse que la tercera calle de Managua era conocida con ese nombre, el campo en mención se ubicaba en su esquina Noreste (El Nuevo Diario, 21/12/2007).

Sobre la participación de la mujer en el deporte durante los años de estudio, Milagros García ha señalado que como consecuencia de la presencia del deporte en la sociedad, una minoría empezaba a ver de buena manera que las mujeres practicaran algunos deportes, siempre que no fueran excesivamente competitivos y que se adaptaran a las características de la fisiología femenina. No obstante, ni la ciencia médica o la sociedad civil en general, consideraban la figura de la mujer deportista. La primera no encontraba en el deporte una actividad recomendable para la salud de las mujeres dada su constitución y la sociedad no admitía la figura que el deporte construía de una mujer decidida, segura e independiente. Así, cuando se empieza a recomendar la práctica física para las mujeres de principio de siglo, como por ejemplo el excursionismo, se hace por unas razones exclusivamente eugenísticas: mejorar la salud de las futuras madres y en consecuencia de los futuros hijos (García, 2001).

Con respecto a los inicios del tenis, se conoce que a mediados de julio de 1913, a los mariners estadounidenses destacados en Managua, les llegarían los útiles necesarios para la práctica del tenis. Esos extranjeros convocarían a algunos de los clubes deportivos nacionales para jugar este deporte (El Comercio, 1913). Para mediados de octubre de 1917, el club de tenis de León jugó un partido en Corinto con el club de ese puerto. Se efectuaron doce encuentros que fueron ganados por el club corinteño, quienes agasajaron a los leoneses con paseos ( $L a$ Noticia, 17/10/1917).

En la tarde del sábado 10 de noviembre de 1917, hubo un torneo de tenis en León. La primera partida de dobles se realizó entre los jugadores del Club Metropolitano Frank May y Dr. Jorge U. Herdocia y los del Club Atlético Luis N. Jiménez y teniente A. C. Dearing. El resultado de los tres sets jugados fue de dos a favor del Atlético y uno a favor del Metropolitano. El resultado general fue de tres partidos ganados por el Atlético y uno ganado por el Metropolitano (El Imparcial, 15/11/1917, p.2).

Acerca de la gimnasia, se sabe que en 1920 , en el programa de las fiesta que se verificó en el Colegio de Varones de Managua, con motivo de los aniversarios xcIx de la Independencia Nacional y LXIV de la Batalla de San Jacinto, sobresale un cuadro de ejercicios físicos por alumnos de esta institución (La Noticia, 
12/09/1920). Con respecto al boxeo, se tiene que para finales de mayo de 1916, don J. Santos Ramírez le daba prácticas científicas de este deporte al joven Isabel Fernández, pitcher del Club Managua. Se creía que se concertaría una pelea en el Teatro Variedades con uno de los mejores boxeadores de Bluefields (La noticia, 03/10/1920). En la noche del viernes 1 de octubre de 1920, don J. Santos Ramírez hijo, había concertado con el atleta holandés de apellido Geerd una pelea de boxeo con una apuesta de cien córdobas. Ramírez consideraba que tres individuos, luchando diez minutos consecutivos cada uno de ellos, podían vencer a Geerd. Las personas escogidas por el señor Ramírez eran los púgiles Cándido Santamaría, "Lolo" y "Toño" Isabá. La pelea se verificó el sábado 9 de octubre del año en mención. Los jueces serian estadounidenses, además de ser presenciado por calificadores expertos como Tomas Martínez, Luis Quezada, Gutiérrez Peña y Francisco Frixione; y los artesanos Carmen Quinto, Alfonso Vega "Jalea", Rafael y Juan Manuel Morales (La noticia, 03/10/1920). Carmen Quinto era pitcher del Boer (La noticia, 26/11/1920).

Sobre la posición de la prensa obrera acerca de la práctica del deporte, Enrique Aquino, quien se inclinaba más por la instrucción $y$ moralización del trabajador que por la ejecución del deporte, escribió en El Esfuerzo Obrero del domingo 26 de setiembre de 1920: "Un hombre forzudo, musculoso y enérgico, pero sin instrucción, testarudo y estúpido, no es un hombre. Las bestias de carga son idénticas" (p.2). La necesidad de instruir al trabajador también la había señalado Sofonías Salvatierra en su libro Azul y Blanco en el año 1919.

En 1921 a raíz de la pelea entre Jack Dempsey y Georges Carpenter, el 2 de julio de ese año, en el Club Social de Managua, lucharon catorce socios, es decir, siete parejas. Pelearon con unos guantes de aficionados que llevó don Benjamín Elizondo R. (La Noticia, 13/07/1921). El domingo 4 de febrero de 1923, pelearon el campeón nacional Enrique Leal y Simón del Carmen, árabe del Monte Líbano. También boxeó el pugilista bluefileño Marcos Padilla, contra seis hombres, pagándoles una buena cantidad por cada round que le soportaran
(La Tribuna, 30/01/1923). Para el 2 de octubre en la Momotombo pelearon el campeón nacional Enrique Leal y el campeón occidental Fernando Rubí. El referee declaró empatada la pelea, pero dos de los árbitros declararon vencedor a Leal por puntos. Antes de este evento principal se realizaron varias peleas preliminares, siendo la más interesante el encuentro entre Ernesto Aguirre "Caimán" y Marco Padilla "Tiburón", ganando Aguirre por knock out (La Tribuna, 04/10/1923).

Con respecto al ajedrez, el domingo 7 de mayo de 1916, el periódico El Heraldo comenzaba la publicación de una sección sobre esta práctica, que saldría todos los domingos ( $E l$ Heraldo, 25/05/1916). Sobre la práctica de esta disciplina, para principios de octubre de 1921, el Club Social de Managua y el Club Social de Granada jugaron tres partidas. La última se efectuó el martes 4 de octubre de ese año. Se había concertado una apuesta de 25 córdobas entre don Carlos Pellas y don Aarón Salomón. Para esta partida se le solicitó la ayuda al señor Miguel Álvarez S., quien había jugado una partida con José R. Capablanca el 14 de enero de 1911 en Nueva Orleans (La Noticia, 13/07/1921). Sobre el Club Social de Granada, fue fundado por el italiano Giacomo "Santiago" Marcenaro, en la "Casa de Vega", el 31 de agosto de 1871 (Belli, Mantica y Caldera, 2011).

En cuanto a los inicios del baloncesto, el domingo 4 de marzo de 1923, los clubes El Alpino y El Deportivo jugaron en La Momotombo un partido de esta disciplina deportiva. A este evento asistió la Banda de los Supremos Poderes. El partido fue presenciado por la alta sociedad capitalina. Ganó el club Alpino, distinguiéndose las señoritas Adelina Espinoza y Elena Castellón. En el Deportivo sobresalió la señorita Graciela Portocarrero (La Tribuna, 06/03/1923). Para el domingo 9 de setiembre del año en mención, se realizaron en el local del cine Margot los ejercicios de práctica del club Deportivo (La Tribuna, 09/09/1923). El 16 de setiembre a las cinco de la tarde, se efectuó un partido con motivo de la inauguración del Club Occidental de Chinandega entre sus equipos Azul y Rojo (La Tribuna, 18/09/1923). Hacia mediados de diciembre de 1923, el Club 
Femenino "El Excelsior" de Jinotepe, creó el club femenino de baloncesto "Iris" (Faces y Facetas, 13/12/1923). En enero de 1924 existían los clubes de baloncesto femeninos "Minerva" de Managua y el "España" de Diriomo (Faces y Facetas, 10/01/1924). Hacia inicios de noviembre de 1923, en Masaya funcionaba el club de baloncesto femenino "Helen" (Faces y Facetas, 08/11/1923). A finales de 1924 se estableció en la capital el club femenino de basketball "Argentino" (Nicaragua Informativa, 22/01/1924). Acerca de las carreras de caballos, en los últimos días de febrero de 1924 funcionaba el Hipódromo de León (La Tribuna, 14/02/1924).

\section{ESTADO, IGLESIA Y CLUBES DEPORTIVOS EN NICARAGUA (1901-1924)}

La posición del Estado en torno a la promoción del deporte en el período de estudio, se manifestó el jueves 22 de marzo de 1906, debido a que el Ministerio de Instrucción Pública distribuyó en los dos centros de enseñanza primaria de Managua, el equipo de gimnasia que le acababan de llegar al gobierno para el servicio de los planteles del país. Este equipo constaba de argollas, perchas, paralelas, escalas y todo lo necesario para promover el desarrollo físico de los niños. Posteriormente, se enviarían a los otros centros de enseñanza de país los equipos que necesitaban (El Comercio, 23/03/1906).

Con respecto a la educación durante el régimen de Zelaya, la reforma curricular de la primaria de 1894, no presentó mayores diferencias con la de 1900. Se incluyó la gimnasia, los ejercicios calisténicos y militares. En 1905, se realizó la reforma de los programas oficiales de primaria, en la cual se contemplaba la educación física; igualmente sucedió en la educación secundaria. Al concluir el período de Zelaya había un total de 643 escuelas primarias. En relación a las 193 que había en 1894, se puede inferir que hubo un crecimiento de unas 450 escuelas primarias, lo que significa que los centros educativos crecieron en un $233,2 \%$. Esto representó un verdadero despegue para la educación (Rodríguez, 1998).

Respecto al control social del Estado sobre la actividad deportiva, se dispone de los estatutos aprobados del Club de béisbol New
York de Managua en 1902, donde se señalan las obligaciones del capitán, del vice capitán, del tesorero, de los socios, el uniforme y el nombre del club (Diario Oficial, 1902).

En los estatutos que el Club Social de Managua presentó en 1911 al Poder Ejecutivo para su aprobación, se señalaba que esta asociación mantendría entre sus servicios privados el de biblioteca, billares, juegos permitidos, cantina y restaurante. Además, señalaba que era ajena a todo propósito religioso y político (Archivo General de la Nación de Nicaragua, 1911).

En 1915, ocurrieron algunos desordenes en varios encuentros de beisbol. Esto llevó a que se emitiera una disposición en la cual se indicaba que en los partidos de cualquier deporte donde existieran apuestas, debían de realizarse en el lugar que señalaran los Jefes Políticos Departamentales. La contravención a esta disposición sería penada con una multa de ocho córdobas, en beneficio de la Junta de Beneficencia donde la hubiera o de los fondos municipales donde no existieran tales juntas. Los partidos antes enunciados no podrían efectuarse en días de trabajo, antes de las cinco de la tarde, salvo que el Jefe Político hubiera concedido permiso. La policía vigilaría estos encuentros y dictaría las medidas necesarias para evitar males mayores (Diario Oficial, 1915). Debido a que esta medida ocurre en un contexto de ocupación militar, se infiere que tenía por objetivo impedir posibles alzamientos políticos.

Aunque el Estado no promocionó ninguna obra sobre deporte, educación física e higiene durante los años de estudio, en 1918 Marco A. Ortega publicó su libro titulado Lecciones de Higiene, en el cual se señala que todo establecimiento escolar de enseñanza debía poseer un departamento especial para los ejercicios de gimnasia, siendo los más recomendados los de gimnasia sueca, la cual era la verdadera gimnasia higiénica. Se prescindiría de los aparatos usados antiguamente, dejando solo aquellos que exigía el método de Ling. El local de gimnasia debía ser ampliamente ancho. En todo establecimiento de enseñanza debían establecerse horas de ejercicio obligatorias para los alumnos, conforme a los principios de la gimnasia sueca. Una o dos veces por mes se debía hacer 
excursiones escolares en las que se obligara a los niños a participar conforme a su resistencia $y$ desarrollo, en jornadas que permitieran el desarrollo general de todos los músculos del cuerpo y a una respiración saludable (Ortega, 1918).

A principios del año de 1877, el acceso a la práctica de la gimnasia y la calistenia se dio en el ámbito de la educación secundaria para una elite económica; no obstante, a partir de 1904 se trata de que se implemente a nivel nacional en la educación primaria. Con la ejecución de los ejercicios militares se pretendía que los niños fortalecieran su conciencia cívica al convertirse en soldados defensores de la soberanía nacional. La prensa nacional trató el tema de la ejecución del ejercicio físico mediante una discusión pedagógica donde la práctica de esta actividad debía de estar acorde con la condición física del niño (Urbina, 2015).

La posición de la iglesia católica en torno a la actividad deportiva se limitó a la entrega de premios y la dirección de ejercicios gimnásticos, lo cual promovió una buena imagen de los sacerdotes que participaban en estos actos culturales. El domingo 25 de febrero de 1917, los estudiantes del Club Patria del Colegio San Juan Bosco de Granada, realizaron sus ensayos gimnásticos en la plazuela de Los Leones. Un nutrido público presenció el evento entre los que destacó el Jefe Político de la plaza. El padre Salvador Boltari dirigió a los jóvenes gimnastas (Diario Nicaragüense, 27/02/1917).

En el acto que organizó la Liga de béisbol de Managua para el domingo 15 de julio de 1917, el Arzobispo José Antonio Lezcano y Ortega, entregó la copa de plata y demás premios al presidente de esta liga, en nombre de la Junta de Beneficencia de Managua (La Tribuna, 12/07/1917).

Con respecto al clero durante los años de análisis, José Santos Zelaya había liquidado el régimen de las manos muertas, expropiando a la Iglesia y secularizando los cementerios. El clero pensó que los conservadores en el poder podrían recuperar sus privilegios, pero no entendieron que la ocupación norteamericana iba a mantener los aspectos capitalistas que el régimen de Zelaya había instaurado. La alta jerarquía había apoyado desde el comienzo a las fuerzas de ocupación. La mayoría del clero era de origen extranjero (Vargas, 1989, p.55). Acerca de la educación durante la ocupación estadounidense, la política del gobierno conservador concedió prioridad a la educación primaria, debido a que la situación económica no permitía dar atención a los centros de secundaria. Se crearon algunas escuelas, especialmente elementales y se dio el mantenimiento mínimo que el presupuesto permitía (Rodríguez, 2005). La inestabilidad política no permitió que el Estado promoviera el deporte a través del sistema educativo a una escala nacional.

Debido a las guerras civiles, los golpes de Estado y la tardía vinculación al mercado mundial a través del café a finales del siglo XIX, la formación de asociaciones deportivas en $\mathrm{Ni}$ caragua en comparación con el resto de países centroamericanos fue bastante pobre, ya que como se verá más adelante es hasta 1901 que se funda la primera asociación deportiva. Acerca de los nombres de los clubes fundados para el período de estudio, se usaron algunos apelativos referentes a lugares, nombres indígenas y héroes aborígenes del país como: Managua, León, Corinto, Granada, Diriamba, Xolotlán, Bluefilds, Nicaragua, Tipitapa, Nueva Segovia, Diriangén, Cocibolca y Tiscapa. También a lugares y hechos históricos extranjeros: New York, Japón, Manchester, Denver, Chile, Filadelfia, Países Bajos, Cleveland, Washington y Boer. La influencia griega también se manifestó en nombres como: Venus, Titán, Minerva, Atenas, Esparta y Marte.

Durante el período de 1901 a 1924, se evidencia que el fenómeno deportivo se concentró en la capital y en la región del Pacifico del país, debido a que esta contaba con las mejores vías de comunicación, infraestructura urbana, centros educativos y el capital necesarios para concertar competencias deportivas. En los años de estudio se establecieron en Nicaragua 81 asociaciones deportivas de las cuales 53 se crearon en Managua (65\%), 8 en Granada (10\%), 4 en León (5\%), 3 en Masaya (4\%), 3 en Chinandega (4\%), 2 en Diriamba (3\%), 2 en Corinto (3\%), 1 en Bluefilds (1\%), 1 en Tipitapa (1\%), 1 en San Rafael del Sur (1\%), 1 en Boaco (1\%), 1 en Ocotal (1\%) y 1 en Somoto (1\%). Sobre la evolución del proceso de fundación de asociaciones deportivas entre 1901 y 1924, se muestra a continuación el gráfico 1 . 


\section{GRÁFICO 1 \\ CLUBES DEPORTIVOS FUNDADOS EN NICARAGUA \\ 1901-1924}

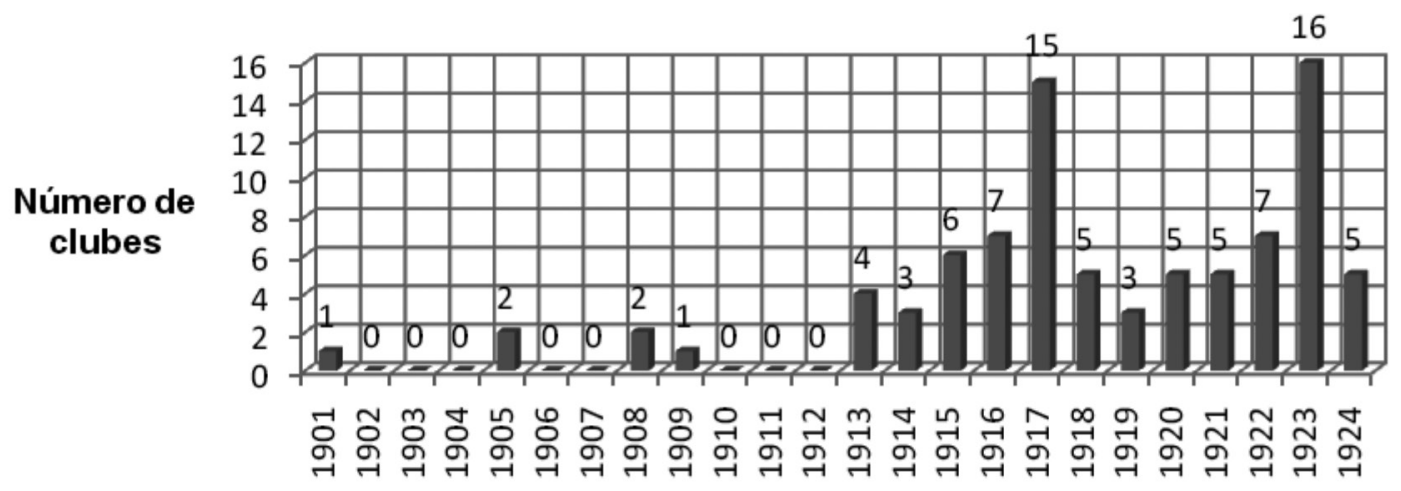

Años

Fuente: Elaboración propia a partir de los datos del Apéndice.

Según se desprende del gráfico 1, entre 1901 a 1912, el origen del fenómeno deportivo en el país fue muy débil —únicamente se crearon 6 clubes - en lo que influyeron factores como la falta de interés en su mantenimiento, la guerra con Honduras de 1907, la caída de José Santos Zelaya en 1909, los alzamientos políticos y la crisis política que hubo en el país previa a la ocupación norteamericana de 1912. A partir de 1913 hasta 1917, se da un crecimiento en el número de asociaciones deportivas donde la concertación de partidos de béisbol entre clubes nacionales $y$ los clubes de los mariners estadounidenses le dio una identificación nacionalista al deporte nacional. Se pasó de 4 agrupaciones en 1913 a 15 en 1917. Después de esto, la fundación de corporaciones deportivas experimentó un proceso de decaimiento pasando de 5 asociaciones en 1918 a 4 en 1924, lo cual se debe a la crisis económica provocada por la Primera Guerra Mundial y a la crisis política del Estado nicaragüense.

\section{CONCLUSIÓN}

Hacia finales del siglo xix, Nicaragua se vincula en forma estable al sistema económico mundial - mediante el cultivo del café - lo cual permitió la llegada de nuevos productos y prácticas culturales, entre estas, el deporte. Al entrar en contacto el país con la economía mundial y el sistema cultural de consumo de masas - lo cual se logró a finales del siglo xix por medio del cultivo y comercialización del café- el nicaragüense comenzó a identificarse con las prácticas deportivas. Según se pudo comprobar es a partir de 1901 que surge la primera asociación deportiva en Nicaragua, la cual al igual que otras corporaciones deportivas tuvo una existencia efímera. Lo anterior se debe a que las primeras asociaciones deportivas nicaragüenses tuvieron una vida muy corta, debido a que su práctica se consideraba como un entretenimiento en el cual no existía disciplina para realizarla. El lugar preferido para la práctica del deporte en los años de estudio, lo constituyó el field de la calle la Momotombo, espacio público y de dimensiones adecuadas para tales actividades, lo que lo convirtió en el sitio de mayor socialización del país. Las primeras disciplinas que surgen son: béisbol, ciclismo, fútbol, atletismo, cricket, tenis, gimnasia, boxeo, ajedrez, baloncesto y carreras de caballos.

El béisbol comenzó a distanciarse y a identificarse más rápidamente entre los nicaragüenses, debido a que los trabajadores empiezan a tomar participación en su práctica. Asimismo, le permitió a los niños el acceso 
a su ejecución y posibilitó la visibilización e integración deportiva de los afrocaribeños del recién incorporado departamento de Zelaya; adquiriendo el carácter de "deporte nacional" debido a la asistencia del presidente Emiliano Chamorro a un partido de esta disciplina deportiva. Este proceso se consolidó cuando el béisbol adquirió el carácter de representación nacional al conquistar el campeonato centroamericano en las Olimpiadas Centroamericanas de Costa Rica en 1924. Sin embargo, la prensa obrera se inclinaba más por la instrucción y moralización del trabajador que por la ejecución del deporte.

Según se pudo comprobar el deporte recibió un exiguo apoyo por parte de la Iglesia y del Estado, lo que hizo que esta actividad no influyera a un nivel nacional en la regeneración de los nicaragüenses, principalmente a través de su enseñanza en el sistema educativo. El fenómeno deportivo se concentró en la capital y en la zona del Pacífico debido a que contaba con las mejores vías de comunicación, infraestructura urbana, centros educativos y el capital necesarios para concertar competencias deportivas.

\section{REFERENCIAS}

Archivo General de la Nación de Nicaragua. (1911). Fondo: Presidencial. Sección: Asociaciones. Club Social de Managua. Caja. 245. Expediente 16.

Arellano, J. E. (2007). La década de los diez del siglo $X X$. Recuperado el 15 de enero de 2015 de http://archivo.laprensa.com. ni/archivo/2007/julio/02/especiales/ reportajes/200216_print.shtml

Arellano, J.E. (2007) El béisbol en Nicaragua. (Rescate histórico y cultural: 18891948). Managua, Nicaragua: Academia de Geografía e Historia de Nicaragua.

Arellano, Jorge Eduardo (2007). "La década de los diez del siglo xx". Recuperado el 15 de enero de 2015 de http://archivo.laprensa. com.ni/archivo/2007/julio/02/especiales/ reportajes/200216_print.shtml

Barahona, L., Salomón y Vivas R., Cesar (ed.) (1972). Guía de la X Serie Mundial de béisbol Amateur. Managua, Nicaragua: Tipografía Pereira.
Belli, C.; Mantica, F. y Caldera, N. (2011). Los italianos en Nicaragua: su aporte al desarrollo económico, social y cultural 1821-1972. Managua:, Nicaragua Impresiones y Troqueles S.A.

Berrios, M. (1960). Juegos nicaragüenses de ayer y de hoy. León. Nicaragua: Editorial Hospicio.

Delgado, J. (1992). Hispanoamérica en el siglo XX. Volumen 18 de Historia General de España y América. Madrid: Ediciones Rialp.

Diario de Nicaragua (14 de septiembre de 1895). Año I. No. 255. Nicaragua.

Diario Oficial (3 de enero de 1902). Tercera Época. Año vir. No.1542. Nicaragua.

Diario Oficial (7 de agosto de 1915). Año XIX. No. 178. Nicaragua.

Dunning, E. (1999). Soccer Hooliganism as a World Social Problem. Mimeo.

El Comercio (14 de julio de 1905). Año X. No. 2550. Nicaragua.

El Comercio (16 de julio de 1913). Año XIX. No. 4779. Nicaragua.

El Comercio (17 de septiembre de 1909). Año xv. No. 3832. Nicaragua.

El Comercio (19 de enero 1908). Año XII. No. 3284. Nicaragua.

El Comercio (20 de agosto de 1913). Año XIX. No. 4802. Nicaragua.

El Comercio (23 de julio de 1905). Año X. No. 2558. Nicaragua.

El Comercio (23 de marzo de 1906). Año X. No. 2755. Nicaragua.

El Comercio (24 de octubre de 1913). Año xxi. No. 5390. Nicaragua.

El Comercio (4 de julio de 1913). Año XVIII. No. 4766. Nicaragua.

El Comercio (7 de noviembre de 1916). Año xxı. No. 5688. Nicaragua.

El Comercio (9 de agosto de 1905). Año X. No. 2570. Nicaragua.

El Diario Nicaragüense (11 de junio de 1915). Año xiI. No. 3484. Nicaragua.

El Diario Nicaragüense (15 de diciembre de 1914). Año xiII. No. 3346. Nicaragua.

El Diario Nicaragüense (2 de marzo de 1920). Año xiII. No. 4315. Nicaragua.

El Diario Nicaragüense (27 de febrero de 1917). Año xiII. No. 3983. Nicaragua. 
El Esfuerzo Obrero (26 de setiembre de 1920). Año I. No. 34. Nicaragua.

El Heraldo (12 de abril de 1918). Año II. No.561. Nicaragua.

El Heraldo (13 de agosto de 1918). Año ir. No. 650. Nicaragua.

El Heraldo (15 de enero de 1918). Año II. No.490. Nicaragua.

El Heraldo (25 de mayo de 1916). Año i. No. 19. Nicaragua.

El Imparcial (15 de noviembre de 1917). Año III. No. 679. Nicaragua.

El Imparcial (2 de octubre de 1917). Año III. No.567. Nicaragua.

El Imparcial (20 de octubre de 1917). Año III. No.659. Nicaragua.

El Imparcial (24 de octubre de 1917). Año III. No. 662. Nicaragua.

El Imparcial (4 de noviembre de 1917). Año iII. No.671.Nicaragua.

El Imparcial (4 de octubre de 1917). Año III. No. 646. Nicaragua.

El Imparcial (7 de diciembre de 1917). Año III. No.698. Nicaragua.

Elias, N. y Dunning, E. (1992). Deporte y ocio en el proceso de la civilización. Madrid: Fondo de Cultura Económica.

Faces y Facetas (10 de enero de 1924). Año 3. No.67. Nicaragua.

Faces y Facetas (13 de diciembre de 1923). Año 2. No.63. Nicaragua.

Faces y Facetas (17 de enero de 1924). Año 3. $\mathrm{N}^{\circ} 68$. Nicaragua.

Faces y Facetas (8 de noviembre de 1923). Año 2. No. 58. Nicaragua.

Falcinelli, H. (ed.) (1898). Guía Ilustrada del Estado de Nicaragua. Octubre de 1898. Roma: Oficina Poligráfica.

García, M. (segundo trimestre 2001). El siglo xx. La revolución deportiva de las mujeres. APunTs. Número Monográfico (64). Recuperado el 11 de enero de 2015 de http://www.nadieseacuerdadenosotras.org/ WEB_SECCIONES_14_8_10/DERECHOS_ MUJERES_REPUBL/PDF_SECCION_ DERECHOS_REPUBLICANOS/La_ revolucion_deportiva_de_las_mujeres.pdf

Guerrero, J. y Soriano de Guerrero, L. (1965). Masaya. Monografía.s.e.
La Noticia ( 9 de agosto de 1921). Año viII. No. 1293. Nicaragua.

La Noticia (12 de setiembre de 1920). Año vi. No. 1041. Nicaragua.

La Noticia (13 de julio de 1921). Año viII. No. 1277. Nicaragua.

La Noticia (17 de octubre de 1917). Año III. No. 578. Nicaragua.

La Noticia (26 de noviembre de 1920). Año vi. No. 1099. Nicaragua.

La Noticia (3 de octubre de 1920). Año vi. No. 1057. Nicaragua.

La Noticia (7 de diciembre de 1920). Año vi. No. 1103. Nicaragua.

La República (5 de septiembre de 1919). Año I. No. 190. Nicaragua.

La Roosevelt pulgada a pulgada antes del gran sismo Managua 72: ¿Qué fue de tanta ilusión? (21 de diciembre de 2007). El Nuevo Diario. Recuperado el 9 de enero de 2015 de http://www.elnuevodiario. com.ni/nacionales/4356

La Tribuna (1 de enero de 1925). J. Año v. No. 1398. Costa Rica.

La Tribuna (4 de enero de 1925). Año v. No. 1400. Costa Rica.

La Tribuna (6 de enero de 1925). Año v. No. 1401. Costa Rica.

La Tribuna (9 de enero de 1925). Año viI. No. 2137. Nicaragua.

La Tribuna (12 de julio de 1917). Año I. No. 73. Nicaragua.

La Tribuna (14 de febrero de 1924). Año viII. No. 1868. Nicaragua.

La Tribuna (18 de junio de 1922). Año vi. No. 1438. Nicaragua.

La Tribuna (18 de setiembre de 1923). Año viI. $\mathrm{N}^{\circ} 1746$. Nicaragua.

La Tribuna (2 de mayo de 1923). Año viI. No.1636. Nicaragua.

La Tribuna (30 de enero de 1923). Año viI. No. 1563. Nicaragua.

La Tribuna (4 de marzo de 1923). Año vil. No. 1592. Nicaragua.

La Tribuna (4 de octubre de 1923). Año viI. No. 1764. Nicaragua.

La Tribuna (9 de setiembre de 1923). Año vil. $\mathrm{N}^{\circ}$ 1741. Nicaragua.

Manfut, E. (2008). "Galería de Alcaldes de Managua 1900-1950”. Recuperado el 17 
de enero de 2015 de http://www.manfut. org/managua/1900.html

Manfut, E. (2008). Galería de Alcaldes de Managua 1900-1950. Recuperado el 17 de enero de 2015 de http://www.manfut.org/ managua/1900.html

McGehee, R.V. (18 al 21 de julio de 2000). El pugilismo en Centroamérica y México, 1900-1927. Ponencia llevada a cabo en el V Congreso Centroamericano de Historia, San Salvador, El Salvador.

Nicaragua Informativa (22 de enero de 1924). Año 8. No. 118. Nicaragua.

Ortega, Marco A. (1918). Lecciones de Higiene. Granada: Tipografía El Centroamericano.

Página Diriamba (2006). Deportes. Recuperado el 2 de enero de 2015 de http://www. diriamba.info/Deportes.htm

Palmer, S. (1996). Racismo intelectual en Costa Rica y Guatemala, 1870 1920. Mesoamérica,(31). Recuperado el el 6 de enero de 2015. de file:///C:/ Users/pc01/Desktop/Dialnet-Racism oIntelectualEnCostaRicaYGuatema la18701920-2466989.pdf

Palmer, S. (2005). Esbozo histórico de la medicina estatal en América Central. Biblid, (25). Recuperado el 6 de enero de 2015 de file:///C:/Users/pc01/ Desktop/114013-142500-1-PB.pdf

Peña, L. M. (22 al 26 de julio del 2002). Un encuentro con la Fundación Rockefeller desde Nicaragua, 19151930. Ponencia llevada a cabo en el VI Congreso Centroamericano de Historia, Universidad de Panamá, Panamá.

Rodríguez, I. (1998). La educación durante el liberalismo, Nicaragua: 1893-1909. Managua, Nicaragua: HISPAMER.

Rodríguez, I. (2005). Historia de la educación en Nicaragua: Restauración
Conservadora (1910-1930). Managua, Nicaragua: HISPAMER.

S.a. (s.f.) "Historia del futbol en Nicaragua". Recuperado el 2 de enero de 2015 de https://kevinrodriguez.wordpress.com/ historia-del-futbol-en-nicaragua/

Salvatierra, S. (1919). Azul y Blanco. Managua, s.ed.

Urbina, C. (2000) Homogeneizando culturas. Peleas de gallos, corridas de toros y estado en Costa Rica (1870-1914). Revista de Ciencias Sociales, (89), pp.59-67.

Urbina, C. (2001). Costa Rica y el Deporte 18731921. Un estudio acerca del origen del fútbol y la construcción de un deporte nacional. Heredia, Costa Rica: EUNA.

Urbina, C. (2006). Origen del Deporte en El Salvador (1885-1943). Realidad $y$ reflexión, (17).

Urbina, C. (2007). Deporte y Nación (18811950). El caso del fútbol en Guatemala. Ciudad de Guatemala: FLACSO.

Urbina, C. (2015). "Ejercicio físico, prensa y Estado en Nicaragua (1877-1904)". Recuperado el 2 de enero de 2015 de http://www.efdeportes.com/efd196/ ejercicio-fisico-prensa-y-estado-ennicaragua1877-1904.htm

Urbina, C. (2015). Ejercicio físico, prensa y Estado en Nicaragua 1877-1904. Recuperado el 2 de enero de 2015 de http://www.efdeportes.com/efd196/ ejercicio-fisico-prensa-y-estado-ennicaragua1877-1904.htm, 2015

Vargas, O. R. (1989). La intervención norteamericana en Nicaragua y sus consecuencias 1910-1925. Managua: DILESA.

Fecha de ingreso: 05/08/2016

Fecha de aprobación:15/02/2017 
CUADRO 1

CLUBES DEPORTIVOS FUNDADOS EN NICARAGUA

1901-1924

\begin{tabular}{|c|c|c|c|}
\hline AÑO DE FUNDACIÓN & $\begin{array}{l}\text { NOMBRE DE LA } \\
\text { ASOCIACIÓN }\end{array}$ & LUGAR DE FUNDACIÓN & DISCIPLINAS DEPORTIVAS \\
\hline 1901 & Club de BaseBall New York & Managua & béisbol \\
\hline $1902-1904$ & --- & --- & --- \\
\hline 1905 & $\begin{array}{c}\text { Veloz Club } \\
\text { Club Ciclista Fernandino }\end{array}$ & $\begin{array}{l}\text { Managua } \\
\text { Masaya }\end{array}$ & $\begin{array}{l}\text { Ciclismo } \\
\text { Ciclismo }\end{array}$ \\
\hline $1906-1907$ & --- & --- & --- \\
\hline 1908 & $\begin{array}{l}\text { Club Managua } \\
\text { Club Unión }\end{array}$ & $\begin{array}{l}\text { Managua } \\
\text { Managua }\end{array}$ & $\begin{array}{l}\text { béisbol } \\
\text { béisbol }\end{array}$ \\
\hline 1909 & Managua Sporting Club & Managua & Fútbol \\
\hline $1910-1912$ & --- & -- & --- \\
\hline 1913 & $\begin{array}{c}\text { Club Boer } \\
\text { Club Venus } \\
\text { Club Japón } \\
\text { Club Emperador }\end{array}$ & $\begin{array}{l}\text { Managua } \\
\text { Managua } \\
\text { Granada } \\
\text { Managua }\end{array}$ & $\begin{array}{l}\text { béisbol } \\
\text { béisbol } \\
\text { béisbol } \\
\text { béisbol }\end{array}$ \\
\hline 1914 & $\begin{array}{c}\text { Granada Sporting Club } \\
\text { Club Diriamba } \\
\text { Club A.B.C. }\end{array}$ & $\begin{array}{l}\text { Granada } \\
\text { Diriamba } \\
\text { Managua }\end{array}$ & $\begin{array}{l}\text { béisbol } \\
\text { béisbol } \\
\text { béisbol }\end{array}$ \\
\hline 1915 & $\begin{array}{c}\text { Club Atlético de Managua } \\
\text { Club Manchester } \\
\text { Club Imperio } \\
\text { Club Xolotlán } \\
\text { Club } 1915 \\
\text { Club de los Mariners } \\
\text { Americanos } \\
\end{array}$ & $\begin{array}{l}\text { Managua } \\
\text { Managua } \\
\text { Managua } \\
\text { Managua } \\
\text { Managua } \\
\text { Managua }\end{array}$ & $\begin{array}{c}\text { béisbol, fútbol, tenis, } \\
\text { patinaje, carreras de autos, } \\
\text { ciclismo y regatas } \\
\text { béisbol y Fútbol } \\
\text { béisbol } \\
\text { béisbol }\end{array}$ \\
\hline 1916 & $\begin{array}{l}\text { Club Electric } \\
\text { Club Denver } \\
\text { Club } 1916 \\
\text { Club Chile } \\
\text { Club Titán } \\
\text { Club Bluefilds } \\
\text { Club America }\end{array}$ & $\begin{array}{l}\text { Managua } \\
\text { Managua } \\
\text { Managua } \\
\text { Managua } \\
\text { Managua } \\
\text { Bluefilds } \\
\text { Granada }\end{array}$ & $\begin{array}{l}\text { béisbol } \\
\text { béisbol } \\
\text { béisbol } \\
\text { béisbol } \\
\text { béisbol } \\
\text { béisbol } \\
\text { béisbol }\end{array}$ \\
\hline
\end{tabular}




\begin{tabular}{|c|c|c|c|}
\hline AÑO DE FUNDACIÓN & $\begin{array}{l}\text { NOMBRE DE LA } \\
\text { ASOCIACIÓN }\end{array}$ & LUGAR DE FUNDACIÓN & DISCIPLINAS DEPORTIVAS \\
\hline \multirow{15}{*}{1917} & Club Carraca & Managua & béisbol \\
\hline & Club Sandoval & Managua & béisbol \\
\hline & Club 1917 & Managua & béisbol \\
\hline & Club Nicaragua & Managua & béisbol \\
\hline & $\begin{array}{c}\text { Club Infantil de béisbol } \\
\text { Filadelfia }\end{array}$ & Managua & béisbol \\
\hline & Club Minerva & Managua & béisbol \\
\hline & Club Atenas & Managua & béisbol \\
\hline & Club Metropolitano & Managua & Fútbol \\
\hline & Club de Chinandega & Chinandega & Fútbol \\
\hline & Club Marino & Managua & béisbol \\
\hline & Club Tipitapa & Tipitapa & béisbol \\
\hline & Club de tenis de León & León & Tenis \\
\hline & Club de tenis de Corinto & Corinto & Tenis \\
\hline & Club América & Managua & béisbol \\
\hline & Club San Fernando & Masaya & béisbol \\
\hline \multirow{5}{*}{1918} & Club de los Paises Bajos & Masaya & béisbol \\
\hline & Club Gigantes & Granada & béisbol \\
\hline & Club Olimpic & Granada & Fútbol \\
\hline & Club Nueva Segovia & Ocotal & béisbol \\
\hline & Club de Somoto & Somoto & béisbol \\
\hline \multirow{3}{*}{1919} & Club 9 Fuertes & Managua & béisbol \\
\hline & Club San Rafael & San Rafael del Sur & béisbol \\
\hline & Club La Escuadra & Managua & béisbol \\
\hline \multirow{6}{*}{1920} & Club de los Hermanos & Managua & Fútbol \\
\hline & Cristianos & & \\
\hline & Club La Estaca & Managua & béisbol \\
\hline & Club La Naranja Agria & Managua & béisbol \\
\hline & Club 1821 & Managua & Fútbol \\
\hline & Club Los Espartanos & Managua & Fútbol \\
\hline \multirow{5}{*}{1921} & Club Cleveland & Managua & béisbol \\
\hline & Club Ultramarinos & Managua & Fútbol \\
\hline & Club Diriangén & Diriamba & Fútbol \\
\hline & Club Social de Managua & Managua & Ajedrez \\
\hline & Club Social de Granada & Granada & Ajedrez \\
\hline \multirow{7}{*}{1922} & Club Atleta & Granada & béisbol \\
\hline & Club Cocibolca & Managua & Fútbol \\
\hline & Club Boston & Managua & béisbol \\
\hline & Club El Federal & Chinandega & béisbol \\
\hline & Club La Libertad & León & béisbol \\
\hline & Club León & León & béisbol \\
\hline & Club Corinto & Corinto & béisbol \\
\hline
\end{tabular}




\begin{tabular}{|c|c|c|c|}
\hline AÑO DE FUNDACIÓN & $\begin{array}{l}\text { NOMBRE DE LA } \\
\text { ASOCIACIÓN }\end{array}$ & LUGAR DE FUNDACIÓN & DISCIPLINAS DEPORTIVAS \\
\hline 1923 & $\begin{array}{c}\text { Club El Deportivo } \\
\text { Club Metropoitano } \\
\text { Club Once Eventh } \\
\text { Club Tiscapa } \\
\text { Club Colón } \\
\text { Club Meridional } \\
\text { Club El Alpino } \\
\text { Club Occidental } \\
\text { Club Quetzal } \\
\text { Club Washington } \\
\text { Club Sporting } \\
\text { Club Iris } \\
\text { Club Minerva } \\
\text { Club España } \\
\text { Club Helen }\end{array}$ & $\begin{array}{l}\text { Managua } \\
\text { León } \\
\text { Managua } \\
\text { Managua } \\
\text { Managua } \\
\text { Managua } \\
\text { Managua } \\
\text { Chinandega } \\
\text { Boaco } \\
\text { Managua } \\
\text { Managua } \\
\text { Jinotepe } \\
\text { Managua } \\
\text { Diriomo } \\
\text { Masaya }\end{array}$ & $\begin{array}{l}\text { Baloncesto } \\
\text { Fútbol } \\
\text { Fútbol } \\
\text { béisbol } \\
\text { béisbol } \\
\text { Baloncesto } \\
\text { Baloncesto } \\
\text { Baloncesto } \\
\text { Baloncesto } \\
\text { Baloncesto } \\
\text { Baloncesto } \\
\text { Baloncesto } \\
\text { Baloncesto } \\
\text { Baloncesto } \\
\text { Baloncesto }\end{array}$ \\
\hline 1924 & $\begin{array}{c}\text { Club Esparta } \\
\text { Club Sporting } \\
\text { Club Infantil Águila } \\
\text { Club Infantil Marte } \\
\text { Club Argentino }\end{array}$ & $\begin{array}{l}\text { Managua } \\
\text { Granada } \\
\text { Managua } \\
\text { Managua } \\
\text { Managua }\end{array}$ & $\begin{array}{c}\text { Fútbol } \\
\text { Fútbol } \\
\text { béisbol } \\
\text { béisbol } \\
\text { Baloncesto }\end{array}$ \\
\hline
\end{tabular}

Fuentes: Diario Oficial (1901-1924), El Comercio (setiembre-diciembre 1903), (enero-diciembre 1904), (enero-diciembre 1905), (enero-diciembre 1906), (enero-octubre 1907), (enero-diciembre 1908), (enero-noviembre 1909), (marzonoviembre 1910), (enero-diciembre 1911), (enero-junio 1912), (abril-diciembre 1913), (enero-diciembre 1914), (enero-diciembre 1915), (julio-diciembre 1916), (mayo-diciembre 1918), (marzo-noviembre 1919), Diario Nicaragüense (noviembre 1910-enero 1912), (diciembre 1912-mayo 1916), Diario de Nicaragua (7 de marzo 1913 15 de marzo 1913), El Heraldo (mayo-agosto 1916), La Noticia (julio 1916-noviembre 1917) y La Tribuna (mayo 1917-octubre 1921), (1922-1924) y (enero 1925).

Nota: $\quad$ El año de fundación corresponde a su aparición en los periódicos. 